\title{
COGNITIVE MAPS AND AHP FOR SUPPLIER SELECTION IN A PRIVATE HIGHER EDUCATION INSTITUTION
}

\author{
Ana Lucia Pegetti \\ University of São Paulo \\ Department of Naval Architecture and Ocean Engineering \\ São Paulo, SP, Brazil \\ E-mail: anapegetti@usp.br \\ Jessé d'Assunção Rebello de Souza Jr \\ São Paulo, SP, Brazil \\ E-mail: jsouza@usp.br
}

\begin{abstract}
Supplier selection is a key decision in the procurement and purchasing processes. Both the choice of criteria and the evaluation of possible alternatives are critical steps in this decision-making. One of the great challenges of private higher education institutions (PHEI) in Brazil in recent decades has been the attempt to institutionalize administrative practices applied in the business market with the primary goal of optimizing their business processes and achieve reduced risks and operational costs, thereby increasing their productivity and the quality of services. These initiatives aim to maintain selfsustaining and competitive institutions in an aggressive market which is constantly expanding. Therefore, a critical and professionalized look at their business processes has been one of the solutions in order for them to achieve their organizational goals. In this context, this paper proposes to formalize the decision-making process in the selection of suppliers through their systematization using cognitive maps to structure and identify the criteria that effectively present value during the partner selection of the decision-maker's procurement and purchasing department. The paper also proposes the subsequent prioritization of these criteria for evaluation and selection of potential suppliers through the use of the AHP multi-criteria method.
\end{abstract}

Keywords: PPS, SODA, Cognitive Maps, AHP. 


\section{Introduction}

In the 90s, the globalization phenomenon triggered the creation of non-higher education systems more compact and focused on specific attributes, in an attempt to fulfill the need for more flexible and transversal qualifications rather than the rigid academic majors offered by the universities. Since then, with the disclosure of the Bases and Guidelines Law in 1996 by the Federal Government, the Brazilian educational segment witnesses a significant increase in the number of higher education institutions, especially private institutions, which increases the competitiveness in the sector and forces these institutions to seek mechanisms to improve their management practices, implementing policies and improving their processes in order to achieve excellence at all organizational levels.

In this context, few studies have been conducted in the field of higher education institutions regarding decision problems related to supplier selection. This is due to the fact that only in recent years PHEI have adopted successful administrative tools which have been consolidated in companies of other segments, with the purpose to perfect their processes and achieve excellence on the services provided. Moreover, the modeling of the decision problems of the aforementioned nature does not follow a specific theoretical framework.

Thus, the use of cognitive maps and the AHP method, both widely used for solving multi-criteria problems, is justified by the existing demand in the Educational Institution to improve their business processes as one of the initiatives to implement strategic actions with the purpose of better allocating institutional resources, which will help make it more efficient and competitive in a hostile and saturated market, reducing operational costs and improving the quality of the services through the consolidation of a supplier network that will contribute with the PHEI's competitive strategy.

\section{Literature Review}

After the identification of the study problem, the needs faced by HEIs to improve their administrative processes and survive market demands and the initiatives implemented in order to achieve this goal were found in the study of Bergamo (2008). Having done this, the next step consisted in evaluating which are the existing approaches for solving supplier selection problems, mainly found in the work of $\mathrm{Wu}$ and Barnes (2012). The next step was to seek specific publications on approaches for structuring decision problems and, in the work of Eden (2004) and Costa (1992), the Strategic Options Development and Analysis (SODA) appeared as a method for working on complex problems. Using interviews and cognitive mapping to capture individual views of an issue, group maps were constructed through the aggregation of individual cognitive maps which were used to facilitate negotiation about value/goal systems, key strategic issues, and option portfolios, identifying the necessary criteria for decision-making and increasing knowledge in the system (process) modeling. Cognitive maps are largely used as a support tool for structuring applications problems, starting from an analysis of cause and effect between the listed criteria and elucidating the relationship between their variables. Once the method of structuring has been defined and after reading the content published on the work of Saaty and Vargas (2006) and other several papers published in ISAHP, we chose to use the AHP method in the final stage of supplier selection, since it has been successfully employed in situations of decision-making that involve 
prioritization, costs and benefits evaluation, resource allocation and strategic decisions, among others.

\section{Hypotheses/Objectives}

The central objective of this research is to define a systematic procedure based on SODA (cognitive maps) and the AHP method to assist the Procurement department of a PHEI to structure their decision-making process of supplier selection as a first step to implement Supply Management on the PHEI.

\section{Research Design/Methodology}

The study was developed in two stages. The first stage involved structuring the decision problem using the SODA methodology proposed by Eden, through the application of cognitive maps. The creation of individual cognitive maps and their subsequent aggregation and congregation (Appendix A) was performed by conducting a series of meetings with two decision-makers, resulting in the multi-criteria model presented in 5 - Data/Model Analysis. We used the Decision Explorer software to build the final map. The following steps were performed: 1. Setting a label for the problem; 2. Definition of the primary elements of evaluation (EPAs); 3. Construction of concepts (cognitive maps) based on EPAs; 4. Construction of the hierarchy of concepts (definition of links-ends, links- means and influence links); 5. Analysis of cognitive map by identifying the concepts head and tail, clusters and lines of argument and branches; 6 . Determination of multi-criteria models by applying the axioms of Costa (1992).

After structuring the multi-criteria model, we used the MakeitRational and SuperDecisions tools to the assessment of the criteria and alternatives through the AHP method (steps of which will not be presented). After applying the method, we proceeded to perform the sensitivity analysis to assess the robustness of the model.

\section{Data/Model Analysis}

Below, the hierarchical model of the problem is presented, as well as the RC calculations regarding the decision-maker's judgment towards the criteria:

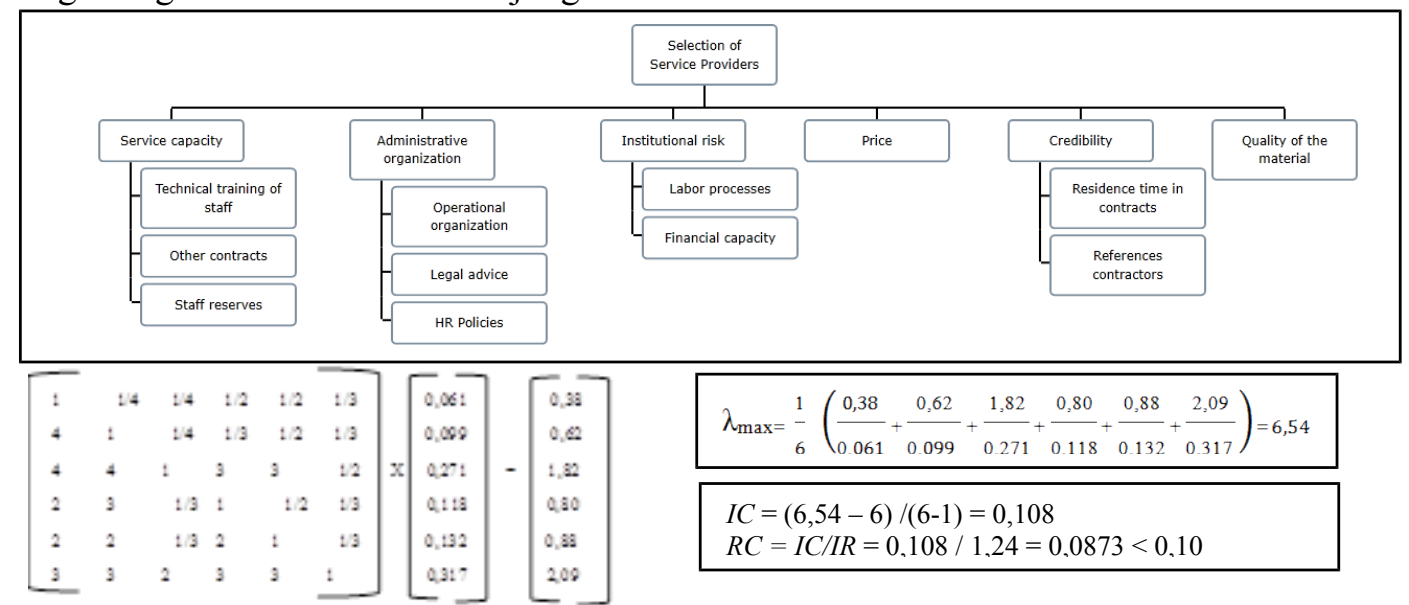

It can be noted that the value obtained for $\mathrm{RC}$ is $<0.10$, which shows consistency on the decision-maker's judgments. The same calculations have been performed for the sub- 
criteria of the model, and for each alternative's judgment towards the criteria, we have achieved $\mathrm{RC}<0.10$.

\section{Limitations}

The major limitation of this study is that it is a case study within education industry; therefore the results may not be applied to supplier selection process in other industries. Another limitation was the size of sample supplier: though the project has successfully implemented AHP approach in the supplier selection process and proposed the final best choice, there still might be better choices outside the candidate pool. Due to the institutional need of an emergency hiring of another company to replace the current provider, only two companies were able to present their proposals. This case study does not have the objective to determine a method for selecting suppliers, nor does it intend to define the criteria which should be considered in problems of supplier prioritization. It limits itself only to present a systematic procedure that allows structuring the decision criteria in a recursive and replicable way. One of the characteristics of the created model is that it does not consider evaluating the current vendor, therefore excluding him from the vendor selection process. Through the analysis of the proposals and without applying the model, we noted a dominance of one company over the other.

\section{Conclusions}

After the completion of this case study, the analyzed PHEI showed interest in applying the method on more strategic business decisions, i.e., to develop other models for the most important and complex decisions. The decision-maker that took part on this study also showed interest in reviewing the model considering the stage of evaluation of the service providers. Regarding the scientific field, the importance of this work is revealing yet another area for application of the cognitive maps associated to the multi-criteria decision-aiding approach (AHP) on decision-making processes linked to vendor selection, with the goal to create the supply chain for a higher education institution, since few studies of this nature have been found, none that use the aforementioned approaches (cognitive maps and AHP) to problem-solving supplier selection on HEIs, specifically.

In short, the AHP method offered an effective and efficient way to select suppliers, incorporating a consistence check to reduce human discrepancy, providing a method that combine objective factors and subjective expert judgments and taking account of both qualitative and qualitative information.

\section{Key References}

(1) Costa, C. A. B. (1992). Structuration, construction et exploitation d'un modèle multicritère d'aide à la décision.

(2) Bergamo, F., Farah, O. E., \& Giuliani, A. C. (2008). A lealdade ea educação superior: ferramenta estratégica para a retenção de clientes. Revista Ibero-Americana de Estratégia-eISSN: 2176-0756, 6(1), 55-62.

(3) Eden, C. (2004). Analyzing cognitive maps to help structure issues or problems. European Journal of Operational Research, 159(3), 673-686.

(4) Saaty, T. L., \& Vargas, L. G. (Eds.). (2006). Decision making with the analytic network process [electronic resource]: economic, political, social and technological applications with benefits, opportunities, costs and risks (Vol. 95). Springer. 
IJAHP Article: Mu, Saaty/A Style Guide for Paper Proposals To Be Submitted to the International Symposium of the Analytic Hierarchy Process 2014, Washington D.C., U.S.A.

(5) Wu, C., \& Barnes, D. (2012). A dynamic feedback model for partner selection in agile supply chains. International Journal of Operations \& Production Management, 32(1), 79-103. 
ISAHP Article: Mu, Saaty/A Style Guide for Paper Proposals To Be Submitted to the International Symposium of the Analytic Hierarchy Process 2014, Washington D.C., U.S.A.

\section{Appendices}
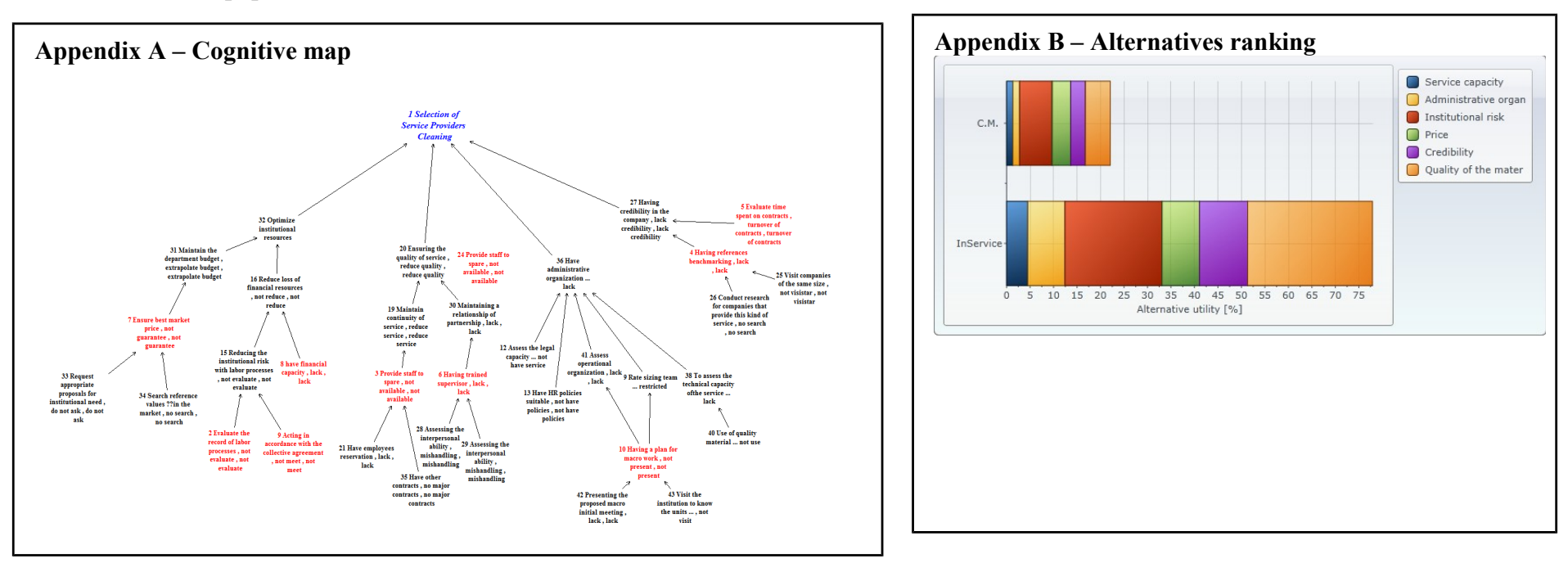

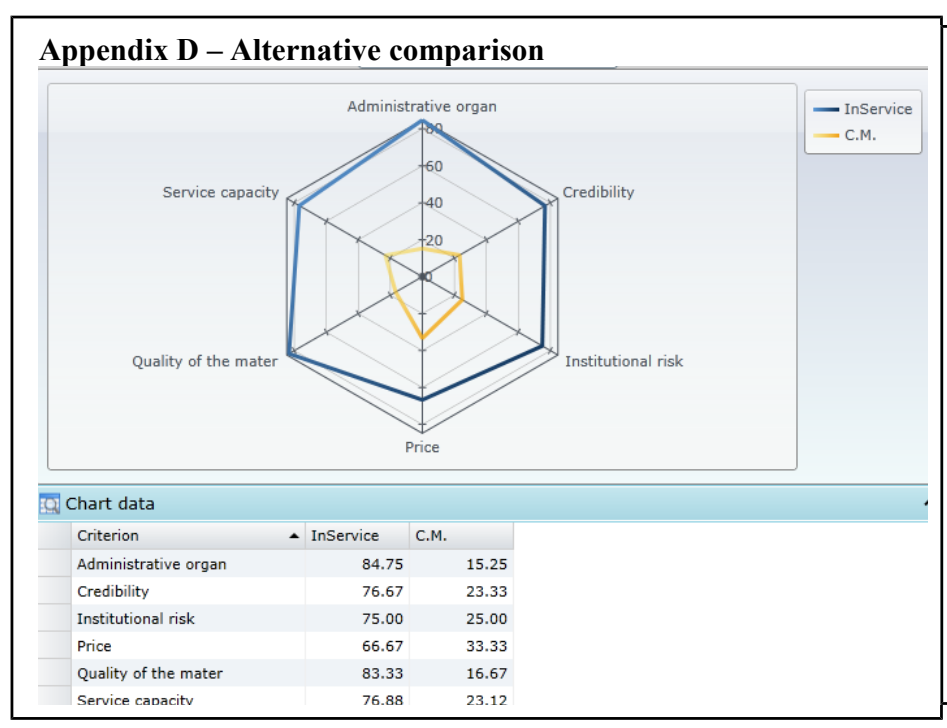

International Journal of the Analytic Hierarchy Process

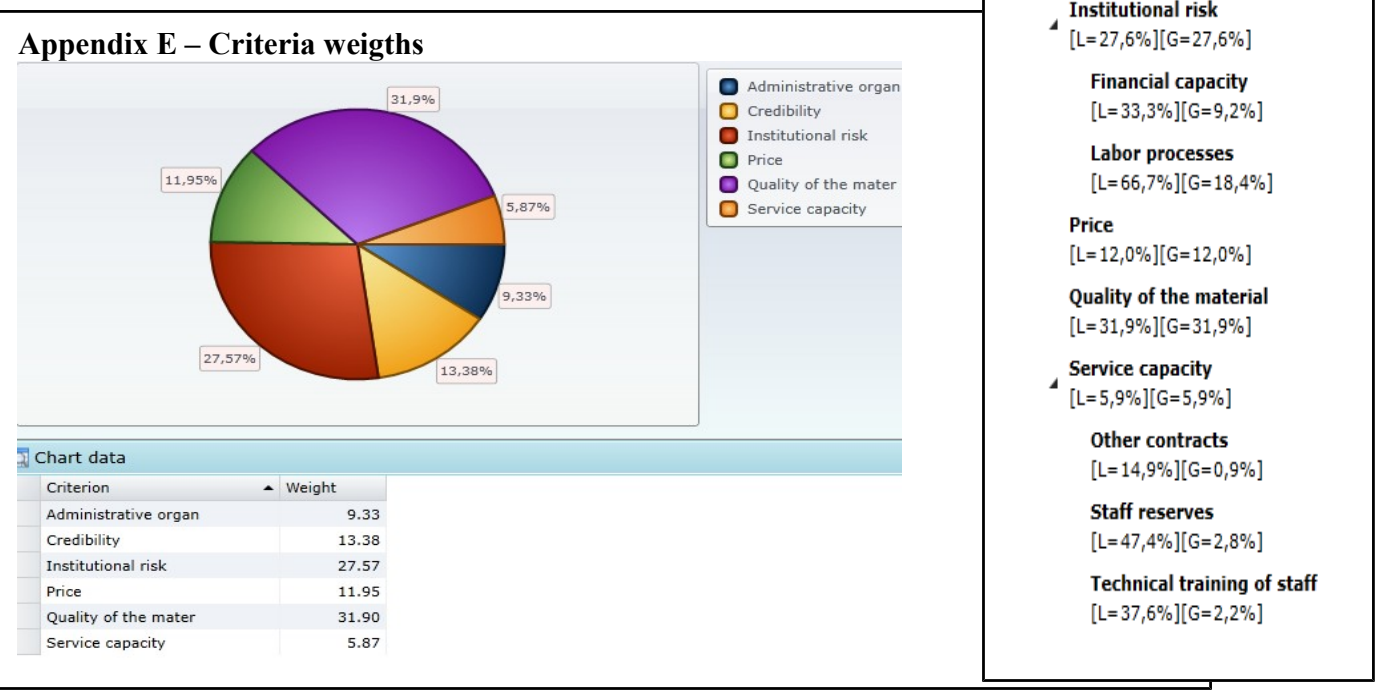

Washington, D.C. June 29 - July 2, 2014

\begin{tabular}{|c|}
\hline $\begin{array}{l}\text { Appendix } C-\text { Criteria } \\
\text { and subcriteria weights }\end{array}$ \\
\hline $\begin{array}{l}\text { Selection of Service Providers } \\
{[L=100,0 \%][G=100,0 \%]}\end{array}$ \\
\hline $\begin{array}{l}\text { Administrative organization } \\
{[\mathrm{L}=9,3 \%][\mathrm{G}=9,3 \%]}\end{array}$ \\
\hline $\begin{array}{l}\text { HR Policies } \\
{[L=59,4 \%][G=5,5 \%]}\end{array}$ \\
\hline $\begin{array}{l}\text { Legal advice } \\
{[L=15,7 \%][G=1,5 \%]}\end{array}$ \\
\hline $\begin{array}{l}\text { Operational organization } \\
{[L=24,9 \%][G=2,3 \%]}\end{array}$ \\
\hline $\begin{array}{l}\text { Credibility } \\
{[L=13,4 \%][G=13,4 \%]}\end{array}$ \\
\hline $\begin{array}{l}\text { References contractors } \\
{[L=20,0 \%][G=2,7 \%]}\end{array}$ \\
\hline $\begin{array}{l}\text { Residence time in contracts } \\
{[L=80,0 \%][G=10,7 \%]}\end{array}$ \\
\hline $\begin{array}{l}\text { Institutional risk } \\
{[\mathrm{L}=27,6 \%][G=27,6 \%]}\end{array}$ \\
\hline $\begin{array}{l}\text { Financial capacity } \\
{[L=33,3 \%][G=9,2 \%]}\end{array}$ \\
\hline $\begin{array}{l}\text { Labor processes } \\
{[\mathrm{L}=66,7 \%][\mathrm{G}=18,4 \%]}\end{array}$ \\
\hline $\begin{array}{l}\text { Price } \\
{[L=12,0 \%][G=12,0 \%]}\end{array}$ \\
\hline $\begin{array}{l}\text { Quality of the material } \\
{[L=31,9 \%][G=31,9 \%]}\end{array}$ \\
\hline $\begin{array}{l}\text { Service capacity } \\
{[L=5,9 \%][G=5,9 \%]}\end{array}$ \\
\hline $\begin{array}{l}\text { Other contracts } \\
{[L=14,9 \%][G=0,9 \%]}\end{array}$ \\
\hline $\begin{array}{l}\text { Staff reserves } \\
{[L=47,4 \%][G=2,8 \%]}\end{array}$ \\
\hline $\begin{array}{l}\text { Technical training of staff } \\
{[L=37,6 \%][G=2,2 \%]}\end{array}$ \\
\hline
\end{tabular}

